\title{
Cross-modality matches suggest anticipated stage fright a multiplicative power function of audience size and status
}

\author{
BIBB LATANÉ and STEPHEN HARKINS \\ The Ohio State University, Columbus, Ohio 43210
}

\begin{abstract}
Subjects adjusted the sound pressure level of a $1,000-\mathrm{Hz}$ tone or the luminance of a $10^{\circ}$ target on a translucent screen to match their anticipated subjective tension in performing before audiences represented by 1-16 color slides of old or young males or females. Consistent with a new theory of social impact, "tension" was a multiplicative power function of the number (exponent $\cong .6$ ) of people in the audience and their ages, with older (37-year-old) audiences generating 2-3 times the tension of younger (teen-age) audiences. Male audiences elicited 5\%-40\% more tension than females.
\end{abstract}

Social impact, broadly defined as any effect of the presence or actions of other people on an individual, can be analyzed as the result of social forces operating in a social force field in much the same way that physical forces operate in physical force fields (Dodd, 1950; Lewin, 1n35; Stewart, 1952; Zipf, 1949; Knowles, Note 1). Given this conception, we should expect that the intensity of a social flux should be determined by factors and laws similar to those that determine, for example, the intensity of a luminous flux. Just as the amount of light falling on a surface is determined by the wattage, proximity, and number of bulbs shining on that surface, so too the effect of other people in a social situation is determined by the importance, closeness, and number of people in that situation. When a person is the target of social forces emanating from other people, then, a new theory of social impact (Latané, Note 2) suggests that the magnitude of those forces should be a multiplicative function of the strength, immediacy, and number of people present.

As in the case of physical stimuli, however, the psychological effect of other people may not be simply a linear function of their number or strength. Rather, social impact may obey psychosocial laws similar to the psychophysical laws which govern the subjective impact of such physical dimensions as sound or light intensity. With respect to increases in the number of people affecting an individual, for

This research was supported by National Science Foundation Grant GS40194 and by a fellowship from the John Simon Guggenheim Foundation to Bibb Latané. Lewis Hinkle built the apparatus, Stanley W. Smith calibrated it, James M. Lynn provided the audiometer for loudness matching, and Marcus $R$. Walker made and provided the sets of slides. We thank W. E. Dawson, H. Garland, J. H. Harvey, P. Isaac, M. R. Jones, L. Krueger, G. Lockhead, G. R. Loftus, L. E. Marks, R. Teghtsoonian, and L. M. Ward for their insightful and very helpful comments on an earlier draft. Request reprints from Bibb Latané, 404C West 17th Avenue, Columbus, Ohio 43210. example, Latané suggests that generally one should expect there to be marginally decreasing impact with the Nth person in the force field adding less than the $(N-1)$ th. Specifically, Latané suggests that there may be a power law of social impact comparable to the power law of psychophysics proposed by S. S. Stevens $(1957,1975)$. Stevens claims that the psychological intensity of a stimulus, $\psi$, will equal a scaling constant, $k$, times the physical intensity of the stimulus, $\phi$, taken to a characteristic power, $\beta$ or $\psi=k \phi \beta$. Likewise, Latané proposes that the psychological impact of other people, I, can be represented as a situational scaling constant, s, times the number of people present, $\mathrm{N}$, taken to some root, $\mathrm{t}$ : or $\mathrm{I}=\mathrm{sNt}$. Since we expect marginally decreasing impact with increases in $\mathrm{N}$, the exponent $\mathrm{t}$ of this power function should be less than 1 .

Finally, the theory differentiates two basic types of social situations which result in two different kinds of social force fields. In the kind of situation we have been considering so far, an individual is the target of social forces emanating from other persons, and increases in the number, strength, or immediacy of these persons should result in increased social impact. We call this multiplication of impact. In a second type of social situation, an individual stands with other people as a member of the group upon which social forces are impinging. In this kind of situation, Latané predicts a diffusion or division of impact such that increases in the size, strength, or proximity of the group should result in decreased effect of outside forces on individual members of the group. As with the multiplication of social impact, the relation between number of people in a group and the resultant impact on an individual should still be a power function with an exponent less than one, but in such cases, we should expect to find inverse power functions, $I=\mathrm{sN}^{-t}$. This process is called the division of social impact. 
Support for the notion of division of impact has been provided by research carried out by Latané and his colleagues. For example, research on bystander intervention has consistently shown that individuals are less likely to respond to an emergency when other people are present than when they are alone (Latané \& Darley, 1970). Also, tipping (Freeman, Walker, Borden, \& Latané, 1975) and trying to pick up dropped coins and pencils (Latané \& Dabbs, 1975) decrease as inverse power functions of group size with exponents of less than one. To date, however, no studies have been reported directly designed to test the relationship between group size and social impact in a multiplicative force field.

The purpose of the present research was to extend this analysis to a situation in which the person is the target of social forces coming from other people, namely, audiences varying in size from 1 to 16 . In addition to determining whether the power law applies when social impact is multiplied, the research involved manipulation of the status of the group which was the source of these pressures, thereby allowing a test of the hypothesis that social impact is a multiplicative function of strength and number.

In this study, we were interested in the intensity of social embarrassment occasioned by appearing in public. Although many of us have been exposed to the embarrassing or even debilitating experience of performing in front of audiences, the mechanism that mediates stage fright or performance apprehension is not at all well understood. Despite a number of discursive treatments in the psychological literature dating back to Woolbert's (1916) interesting analysis of the audience [and, of course, phenomenological treatments in sociology (Goffman, 1959), literature, and drama], there has been relatively little systematic empirical research on embarrassment or stage fright.

Zajonc (1965) marshals impressive evidence for the proposition that the mere presence of a passive audience should impair the learning of new responses but facilitate the performance of those that have already been learned, and this proposition has stood up reasonably well to further empirical test (e.g., Martens, 1969). Zajonc links up his proposition to Hull-Spence learning theory and suggests that the presence of others leads to the arousal of $D$ and a concurrent increase in the probability of dominant responses. The implications of social facilitation theory (see also Cottrell, 1972) for embarrassment or performance apprehension are not clear.

Modigliani (1968) believes that embarrassment should be greater in front of strangers than in front of friends, but Brown and Garland (1971) have found data consistent with an opposite interpretation. Using the devilish task of asking people to sing "Love is a Many-Splendored Thing" in front of bogus audiences (see also Brown, 1970; Brown, Garland \& Mena, 1971; Garland \& Brown, 1972),
Brown and Garland found that people sing longer in front of strangers than in front of friends, presumably because they are less embarrassed.

Brenner (Note 3) employed a psychological stress evaluator to analyze the degree of square and diagonal blocking in the voice patterns of students reciting Edgar Allan Poe's "The Bells" before audiences ranging from 0 to 22 spectators. Walker (1974) asked subjects to make category judgments and magnitude estimates of how nervous they would feel while singing in front of audiences ranging from 1 to 16 members. Both report that tension seems to grow as a power function of audience size.

To follow up on these intriguing starts, we turned to a less involving but more controllable task: we used cross-modality matching techniques developed in the study of sensory psychophysics. Subjects were asked to imagine that they had memorized a poem which was to be recited in front of audiences varying in size and status and to estimate the amount of tension or anxiety they would experience by adjusting the luminance of a translucent screen or the intensity of a $1,000-\mathrm{Hz}$ tone to match.

The use of such cross-modality matching measures in the study of social psychological phenomena follows the lead of Dawson and Brinker (1971), whose subjects adjusted loudness, force of handgrip, and apparent duration to match the strength of their opinions regarding racism, occupational desirability, and pronounceability of trigrams. Dawson (1975) and his colleagues (Brennan, Ryan, \& Dawson, 1975; Dawson \& Mirando, 1975, 1976) term the method sensory-modality matching since it involves adjusting one sensory modality to a set of items of stimuli not belonging to a simple sensory continuum. Other experimenters (Hamblin, 1971; Künnapas \& Wikström, 1963; Shinn, 1969; Welch, 1971) have used magnitude estimation in their study of social psychological variables; Stevens (1966, 1975) has described these and other efforts to develop a "metric for the social consensus."

We made the following predictions: (1) The number of persons in an audience and tension will be related by a power function with an exponent of less than one; (2) this exponent will be approximately the same regardless of the modality used (i.e., brightness or loudness); and (3) audiences composed of older, higher status people should engender more tension, and, since it is postulated that audience size and status are multiplicatively related, there should be greater differences for larger audiences.

\section{METHOD}

Subjects

Twenty-six Ohio State University undergraduates volunteered in order to fulfill a Psychology 100 course requirement and were tested individually in a single hour-long session. Ten participated in the preliminary experiment described below, 16 in the main experiment. 


\begin{abstract}
Apparatus
The luminance of a 4-in. circle on a translucent screen approximately $2 \mathrm{ft}$ in front of the subject and subtending a visual angle of $10^{\circ}$ could be controlled by adjusting the voltage impressed on a $200-\mathrm{W}$ bulb in $5-\mathrm{V}$ steps ranging from 35 to $90 \mathrm{~V}$. A Maico audiometer was used to vary the intensity of a $1,000-\mathrm{Hz}$ tone in 5-dB steps ranging from 42 to $97 \mathrm{~dB}$. The tone was monaurally presented over TDH 39 headphones, with the ear used (right or left) determined randomly for each subject.
\end{abstract}

\section{General Procedure \\ Subjects were tested individually in a soundproof booth. They were informed that brightness or loudness could be increased in intensity by pressing one button, decreased in intensity by pressing another button, and would remain constant if neither button was pressed. Students then practiced controlling the intensity of both brightness and loudness. Stimuli were presented in randomly determined sequences, with the exception that subjects made all their matches within a given pair of modalities at one time.}

\section{Preliminary Experiment}

After familiarization with the response modes, 10 subjects made magnitude estimates of both loudness and brightness using a free modulus procedure in which they could assign whatever number they deemed appropriate to the first stimulus but had to assign later numbers in proportion to the apparent intensity of the stimulus. Fractions were allowed but zero and negative numbers were not. Subjects made magnitude estimates for 12 luminances ranging from 2.8 to $251 \mathrm{fL}$, as measured by a Pritchard photometer, and 12 sound-pressure levels ranging from .025 to 14.16 dynes $/ \mathrm{cm}^{2}$.

A second pair of tasks involved magnitude production for brightness and loudness. The experimenter read a series of 12 numbers ranging from 1.25 to 100 over the intercom, and the subjects adjusted brightness or loudness levels to match.

\section{Main Experiment}

Sixteen subjects completed four cross-modality matching tasks. In two, subjects were asked to adjust brightness to match 12 sound-pressure levels or to adjust loudness to match 12 levels of luminance. For the other two tasks, the subjects were asked to imagine that they had memorized a poem and were to recite it in front of an audience, colored slides of whose faces would be presented.

"Audiences" consisted of $1,2,4,8$, or 16 faces of persons, either males or females, either in their early teens or in their late $30 \mathrm{~s}$, sequentially presented at the rate of $1 / \mathrm{sec} .{ }^{1}$ The subjects saw two replications of Audience Size 1 and one replication of Audience Size 2, 4, 8, and 16, thereby making six judgments within each age-sex category. Audiences were composed randomly for each subject, with different slides for the brightness and loudness matches, and were presented in a randomly determined order which differed for each subject. Altogether, the subjects saw slides of 128 different people, but each person was seen twice in different audiences. The subjects were asked to make the screen as bright or the tone as loud as they would be anxious, nervous, or tense if they were asked to recite a poem in front of an audience composed of the persons whose faces had just been shown to them.

\section{RESULTS}

\section{Exponents for Loudness and Brightness}

Since the existence of a power law implies that relationships should be linear in log-log coordinates, the magnitude estimation and production data from the preliminary experiment were expressed in logarithmic units and subjected to one-way analyses of variance with $\log$ stimulus level as the factor. ${ }^{2}$ Although there were significant but slight deviations from linearity for brightness estimation $[F(10,99)=$ 3.3 ] and production $(F=2.2)$ and for loudness production $(F=6.6)$, the proportions of the total variance accounted for by the overwhelming linear trends ranged from $61 \%$ for brightness estimation to $85 \%$ for loudness estimation, $92 \%$ for loudness production, and $93 \%$ for brightness production. ${ }^{3}$ Thus, the present setting produces very good, but not quite perfect, power functions.

The exponent for the power function implied by the loudness estimation data is .45 and by the loudness production data, .61. Taking the geometric mean of these exponents to control for regression effects as suggested by Stevens and Greenbaum (1966) results in an exponent of .52, which is the exponent for loudness in this setting. This approximates the median value of .54 found in a distribution of 71 estimates of loudness exponents compiled by Marks (1974). Although it is lower than the value of .67 recommended by Stevens (1972), it is similar to the value of .54 reported by Stevens (1961) for monaural presentation.

The exponent for the power function implied by the brightness estimation data is .41 and by the brightness production data, .71. The geometric mean of these exponents is .54, which is the exponent for brightness in this setting. This exponent is higher than the .33 recommended by Stevens (1975), but subjects were not dark adapted since they would be required to view slides.

\section{Cross-Modality Matches of Brightness and Loudness}

The data from the main experiment were transformed into $\log$ units and subjected to one-way analyses of variance. Although there were again slight, but significant, deviations from linearity for both the loudness to light $[F(10,165)=2.5)]$ and brightness to sound matches $(F=2.1)$, the linear trends again were overwhelming, accounting for $95 \%$ and $93 \%$ of the total variance. These linear trends imply exponents of 1.26 and .94, respectively, which produce a geometric mean of 1.08 . This experiment should represent the ratios of the exponents for brightness and loudness, and is reasonably close to the value of 1.04 achieved in the preliminary experiments with magnitude estimation and production techniques.

\section{Cross-Modality Matches of Psychosocial Stimuli}

The data were again transformed into logarithmic units and analyzed in 2 by 2 by 5 within-subject ANOVAs with the sex, the age, and the log of the size of the audience as factors. Since, unless otherwise noted, all $\mathrm{p}$ values were less than .01 , we present 
$\omega^{2}$, the proportion of variance accounted for, as a guide to the size of ef fects.

As audience size increased, subjects matched their subjective tension with increasing loudness of tone $\left[F(1,15)=47.3, \omega^{2}=56 \%\right]$. The linear component accounted for $99 \%$ of the variance attributable to audience size $[F(1,60)=186]$, and deviations from linearity (that is, deviations from a power function) were not significant, $[F(3,60)=.56, p=.65]$.

The slope of this linear trend, and therefore the exponent of the power function implied by it, was found to be .99 . Since in cross-modality matching this exnonent should represent the ratio of the exponent for effect of audience size and the exponent for loudness, and since the exponent for loudness in this setting is .52 , this result implies that the exponent for the effect of audience size on rated tension is about .52 .

Figure 1 displays the relationship between audience size and status and loudness matches plotted in logarithmic coordinates. As noted above, the linear fit implies a power function. As can be seen in Figure 1, subjects indicated that audiences in their late 30s engendered more anxiety than audiences in their young teens $\left[\mathrm{F}(1,15)=46.1, \omega^{2}=12 \%\right]$. In addition, male audiences elicited more tension than did female audiences $\left(F=16.5, \omega^{2}=5 \%\right)$.

As audience size increased, subjects also matched ineir subjective tension with increasing brightness of screen $\left[F(1,15)=45.0, \omega^{2}=63 \%\right)$. The linear component accounted for $97 \%$ of the variance attributable to audience size $[F(1,60)=175)$. Again, there were no significant deviations from linearity (i.e., from a power function) $[F(3,60)=1.67$, $p>$.20]. The exponent for the power function implied by this linear trend was found to be 1.11. Since the exponent for brightness in this setting is .54 , this result implies that the exponent for the effect of audience size on rated tension is about .60 .

As in the analysis of loudness matches, subjects indicated that audiences in their late $30 \mathrm{~s}$ aroused more anxiety than audiences in their early teens $\left[F(1,15)=43.8, \omega^{2}=16 \%\right]$. In addition, the effect of sex of audience approached conventional significance levels $\left(F=2.81, p<.12, \omega^{2}=1 \%\right)$, with male audiences causing more tension than female audiences.

There were no interactions between age or sex and audience size ( $p s>.20)$. Since age and audience size did not interact, the main effects for these variables, expressed in log units, imply an additive relationship. However, adding logs is the same as multiplying the antilogs, and thus the data are consistent with the hypothesis that impact is a multiplicative function of status and number. This multiplicative relationship results in there being greater differences due to age and status for the larger audience sizes. Figure 2 displays this multiplicative relationship in

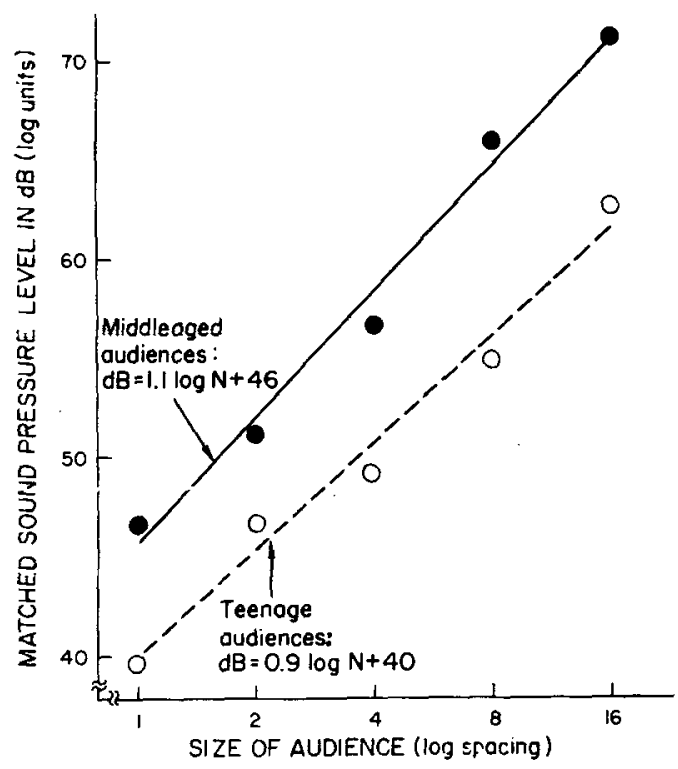

Figure 1. Social tension as indicated by adjusted sound pressure level in decibels as a function of audience size (log spacing) and status.

normal units for the brightness matches; the comparable relationship for loudness is similar in form.

The lack of interactions between audience size and status in log units also implies that the slopes, and therefore the exponents, for the high and low status audiences do not differ, ${ }^{4}$ while the main effects for status imply differences in unit value. The ratio of the sound pressure levels accorded old and young audiences was 1.95; the ratio of the comparable luminances was 2.96. Subjects thus appear to be

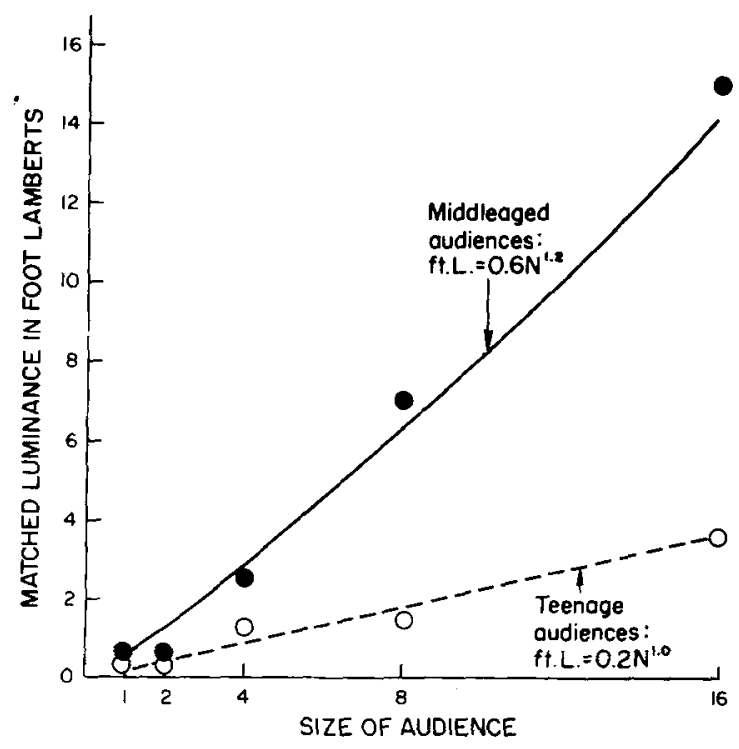

Figure 2. Social tension as indicated by adjusted luminance in foot lamberts as a function of audience size and status. Note change to linear coordinates to display multiplicative relationship of size and status. 
telling us that the 37-year-old audiences were 2 to 3 times as tension arousing as the teenage audiences. Sex differences were not as pronounced; on loudness matches, males were seen as generating $40 \%$ more tension but only $5 \%$ more on brightness matches.

\section{DISCUSSION}

It is probably no surprise to psychologists familiar with cross-modality matching that people can do a good job on these tasks, but we were impressed by the remarkable ease and confidence with which our subjects made these unusual comparisons. Not only were subjects able to equate such disparate commodities as nervousness, loudness, and brightness, but they did so in an impressively lawful manner.

The generality of these results may be limited by the fact that they are based on subjective estimates about reactions to imagined situations. One problem with subjective estimates is uncertainty about their relationship with underlying psychological structures. Although Anderson (1972) and others have presented persuasive arguments challenging the validity of magnitude estimation and other forms of cross-modality matching as measures of true sensation, other work in our laboratory (Walker, 1974) and elsewhere (Curtis, Attneave, \& Harrington, 1968; Marks, 1974; Ward, 1972) has shown that similar power functions obtain with the use of category rating scales as with magnitude estimation.

A second problem with subjective estimates is their potential responsiveness to such sources of bias as experimenter demand. Although cross-modality matching cannot prevent subjects from responding to the experimenter's expectations with regard to the existence or direction of effects, the complexity of the transductions involved would seem to make it unlikely that subjects are merely responding to demand characteristics with respect to the shape of the function. The fact that we found the same functions and approximately the same exponent whether subjects adjusted loudness or brightness increases our confidence that both results reflect the same underlying relationship.

Results of an experiment on stuttering reported by Porter (1939) provide evidence that the relationship we found between stage fright and audience size may also hold in situations involving natural behavior and real audiences. In that experiment, 10 male and 3 female stutterers, all receiving remedial speech instruction at the University of Iowa, were asked to read 500-word passages in front of audiences consisting of $0,1,2,4$, and 8 members. Since stuttering is a behavioral response to the tension and nervousness induced by public performance, social impact theory would predict that it should grow as a power function of audience size with an exponent less than one. In fact, our re-

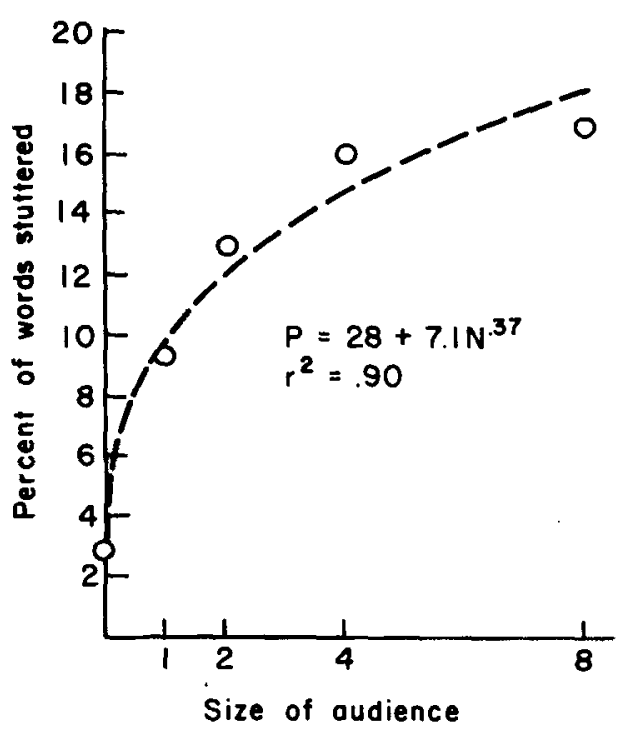

Figure 3. Stuttering as a function of audience size (Porter, 1939).

analysis of Porter's data (the open circles in Figure 3) shows that the best-fitting power function (the dashed line) accounts for $90 \%$ of the variance and has an exponent of about .4 .

The results were generally consistent with social impact theory, which suggests that stage fright, like many other social phenomena, can be analyzed as resulting from the operation of social forces in a social force field. Consistent with this conception, subjects anticipated more tension in performing before audiences that presumably should generate strong social forces (larger numbers of older, betterdressed people) than before audiences which could be expected to generate a less intense social flux (small numbers of young people) and the number and age-status of the people in the audience seemed to combine as a simple multiplicative function rather than additively.

A second principle of social impact theory is that impact should obey a psychosocial law similar to Stevens' psychophysical law. Analysis showed that subjective estimates of stage fright and audience size were related by a power function with an exponent less than one. As expected, performance anxiety was a direct function of, but did not grow so fast as, the number of people in the audience. Differences in the age and status of the audience affected the unit values, not the exponent of the power function, thereby being expressed in the multiplicative constant $s$ of the power function: $I=s N^{t}$.

Since status was not quantified in the present experiment, the relationship between status and $s$ is unknown. We cannot specify the form of the relationship beyond stating that perceived tension appears to be a multiplicative function of some function of status and a power function of size. It would be 
interesting to scale status so that the form of this function could be determined. Tension may well also be related to status by a power function.

Probably no one is too surprised to learn that performance apprehension is larger when one expects to appear before a large audience of middle-aged males than before a small number of teenagers. The use of psychophysical techniques, however, has given us a precise test of the form of the relationship between group size and social tension, ratio measures of the effects of age and sex on anxiety, and a demonstration of the multiplicative relationship between size and status. We think these accomplishments attest to the continued vitality of psychophysical concepts and techniques and their applicability to new areas of inquiry.

\section{REFERENCE NOTES}

1. Knowles, E. S. The gravity of crowding: The application of social physics to the effects of others. Unpublished manuscript, University of Wisconsin-Green Bay, 1975.

2. Latané. B. A theory of social impact. Paper presented at the Annual Meeting of the Psychonomic Society, 1973.

3. Brenner, M. Stagefright and Stevens' law. Paper presented to the Eastern Psychological Association, 1974.

\section{REFERENCES}

ANDERson, N. Cross-task validation of functional measurement. Perception \& Psychophysics, 1972, 12, 389.395.

Brennan, E. M., Ryan, E. B., \& Dawson, W. E. Scaling of apparent accentedness by magnitude estimation and sensory modality matching. Journal of Psycholinguistic Research, 1975, 4, 27.36.

Brown, B. R. Face-saving following experimentally induced embarrassment. Journal of Experimental Social Psychology, $1970,6,255-271$.

Brown, B. R., \& Garland. H. The effects of incompetency, audience acquaintanceship and anticipated evaluative feedback on face-saving behavior. Journal of Experimental Social Psychology, 1971, 7, 490-502.

Brown, B. R., Gardand, H., \& MENA, M. Effects of another's dependency and expectations of meeting with him on the reduction of face-saving behavior. Proceedings of the 79th Annual Convention of the American Psychological Association, 1971, 6. 299-300. (Summary)

Cotrrell, N. B. Social facilitation. In C. S. McClintock (Ed.), Experimental social psychology. New York: Holt, Rinehart, \& Winston, 1972. Pp. 185-236.

Curtis, D. W., Atrneave, F., \& Harrington, T. L. A test of a two-stage model of magnitude judgment. Perception \& Psychophysics, 1968, 3, 25-31.

Dawson, $\mathbf{W}$. E. An assessment of ratio scales of opinion produced by sensory-modality matching. In H. R. Moskowitz, B. Scharf, \& J. C. Stevens (Eds.), Sensations and measurement. Dordrecht. Holland: D. Reidel, 1975.

Dawson, W. E., \& Brinker, R. P. Validation of ratio scales of opinion by multimodality matching. Perception \& Psychophysics, 1971, 9, 413-417.

Dawson, W. E., \& Mirando, M. A. Sensory-modality opinion scales for individual subjects. Perception \& Psychophysics, 1975, 17. 596-600.

Dawson. W. E., \& Mirando, M. A. Inverse scales of opinion obtained by sensory-modality matching. Perception and Motor Skills, 1976, 42, 415-425.
DoDd, S. C. The interactance hypothesis: A gravity model fitting physical masses and human groups. American Sociological Review, 1950, 15, 245-256.

Freeman, S., Walker, M., Borden, R., \& Latané, B. Diffusion of responsibility and restaurant tipping: Cheaper by the bunch. Personality and Social Psychology Bulletin, 1975, 1, 584-587.

Garland, H., \& Brown, B. R. Face-saving as affected by subjects' sex, audiences' sex and audience expertise. Sociometry, 1972 , 35, 280-289.

Goffman, E. The presentation of self in everyday life. New York: Doubleday, 1959.

GreEnhouse, M., \& Geisser, T. On methods in the analysis of profile data. Psychometrika, 1959, 24, 95.112.

Hamblin, R. L. Mathematical experimentation and sociological theory: A critical analysis. Sociometry, 1971, 34, 423-452.

KüNNAPAS, T., \& WIKSTRöм, I. Measurement of occupational preferences: A comparison of scaling methods. Perceptual and Motor Skills, 1963, 17, 611-614.

LATANÉ, B., \& DARLEY, J. M. The unresponsive bystander: Why doesn't he help? New York: Appleton-Century-Crofts, 1970.

Latané, B., \& Dabis, J. Sex, group size and helping in three cities. Sociometry, 1975, 38, 180-194.

LEWIN, K. A dynamic theory of personality: Selected papers of Kurt Lewin. New York: McGraw-Hill, 1935.

Marks, L. E. On scales of sensation: Prolegomena to any future psychophysics that will be able to come forth as science. Perception \& Psychophysics, 1974, 16, 358-376.

MARTENS, R. Effect of an audience on learning of a complex motor skill. Journal of Personality and Social Psychology, 1969, 12, 252-260.

Modigliani, A. Embarrassment and embarrassability. Sociometry, 1968, 31, 313-326.

Porter, H. Studies in the psychology of stuttering. XIV. Stuttering phenomena in relation to size and personnel of audience. Journal of Speech Disorders, 1939, 4, 323-333.

SHins, A. An application of psychophysical scaling techniques to the measurement of national power. Journal of Politics, 1969, 31. 932-951.

Stevens, S. S. On the psychophysical law. Psychological Review, 1957, 64, 153-181.

Stevens, S. S. To honor Fechner and repeal his law. Science, 1961, $133,80-86$.

Stevens, S. S. A metric for the social consensus. Science, 1966, 151, 530-541.

Stevens, S. S. Perceived level of noise by Mark VII and decibels. Journal of the Acoustical Society of A merica, 1972, 51, 575-601.

STEVens, S. S. Psychophysics: Introduction to its perceptual, neural and social prospects. New York: Wiley, 1975.

Stevens, S. S., \& Greenbaum, H. B. Regression effect in psychophysical judgment. Perception \& Psychophysics, 1966, 1, 439-446.

STEWART, J. Q. A basis for social physics. Impact of Science on Society, 1952, 3, 110-133.

TESSER, A., \& ConleE, M. C. Some effects of time and thought on attitude polarization. Joumal of Personality and Social Psychology, 1975, 31, 262-270.

WALKER, R. Group size and psychosocial judgment. Unpublished masters' thesis, The Ohio State University, 1974.

WARD, L. M. Category judgments of loudness in the absence of an experimenter-induced identification function: Sequential effects and power function fit. Journal of Experimental Psychology, 1972, 94, 179-184.

WELCH, R. The use of magnitude estimation in attitude scaling: Constructing a measure of political dissatisfaction. Social Science Quarterly, 1971, 52, 76-87.

Woolbert, C. H. The audience. Psychological Monographs, 1916, 21, 37-54.

Zajonc, R. B. Social facilitation. Science, 1965, 149, 269-274.

ZIPF, G. K. Human behavior and the principle of least effort. Cambridge, Mass: Addison-Wesley, 1949. 


\section{NOTES}

1. A reviewer notes a possible confounding between audience size and the time available to subjects to think about their judgment. We considered using photographs of different sized groups (and indeed conducted preliminary research with such slides). However, this alternative procedure might have resulted in problems stemming from the fact that audience members would vary in image size and would tend to obscure each other in larger audiences. Although our preliminary work with group pictures led to strong group size effects as predicted, we adopted sequential presentation in the main experiment since the problems of time differences (Tesser \& Conlee, 1975) seemed less bothersome than the confounds resulting from the use of group photographs.

2 . The conservative degrees of freedom suggested by Greenhouse and Geisser (1959) for within-subjects effects were used for all analyses. Unless otherwise specified, all $\mathrm{p}$ values are twotailed and less than .01.

3. These proportions are of the total variance in individual judgments and are quite impressive. In terms of the more conventional style of reporting, power functions accounted for $92 \%$ $99 \%$ of the variances among the means.

4. As a further test, individual exponents were calculated for each age-sex combination for each subject for both brightness and loudness. These data were analyzed in 2 by 2 within-subject ANOVAs with age (early teens vs. late $30 \mathrm{~s}$ ) and sex of audience as factors. There were no differences in exponent due to age or sex for either brightness, ps $>.30$, or loudness, ps $>.10$.

(Received for publication March 19, 1976; revision accepted September 10, 1976.) 